\title{
Efeito da administração de cogumelo tibetano, um consórcio microbiano, sobre a peristalse intestinal em ratos
}

\author{
Luiz G.V. Cardoso' ${ }^{1}$ José M. Schneedorf ${ }^{1}$, João E. Fiorini ${ }^{2}$, Bianca R. de Oliveira ${ }^{1}$, José C.T. \\ Carvalho $^{1^{*}}$ \\ ${ }^{1}$ Laboratório de Fitofármacos, Universidade de Alfenas, Rod. MG 179, km 0, \\ CP 23, 37130-000, Alfenas, Minas Gerais, Brasil, \\ ${ }^{2}$ Laboratório de Biologia e Fisiologia de Microorganismos, Universidade de Alfenas, Rod. MG 179, km 0, \\ 37130-000, Alfenas, Minas Gerais, Brasil
}

\begin{abstract}
RESUMO: O cogumelo tibetano (CT) é uma bebida probiótica fermentada por um grande conjunto de bactérias e leveduras, algumas das quais de conhecida atividade antimicrobiana, imunomodulatória, pró-digestiva e auxiliar da peristalse intestinal. Neste sentido, este trabalho teve como objetivo avaliar a possível ação da suspensão produzida pelo CT sobre a motilidade intestinal de ratos. Foram utilizados grupos de animais (ratos Wistar albinos machos, $n=6 /$ grupo) pesando $200 \pm 20$ g. Os diferentes grupos foram tratados v.o. durante 15 dias (1,5 mL/animal de fermentado de 24 h de CT em cultivo contínuo em 50 g/l de açúcar mascavo comercial em água destilada), e os demais grupos tratados com água destilada (1,5 mL/animal). Após 15 dias os animais foram mantidos em jejum por 24 hs, e tratados com suspensão de CT (1,5 mL/animal/v.o), água destilada (controle, 1,5mL/animal/v.o), acetilcolina (1mg/kg/s.c.) e atropina (1mg/kg/i.m.). Após $30 \mathrm{~min}$, os animais receberam uma suspensão de carvão ativo $10 \%(0,1 \mathrm{~mL} / 10 \mathrm{~g}$, v.o), seguindo-se eutanásia após 45 min, excisão da porção do piloro até o início do ceco, e determinação da distância percorrida pelo carvão. A administração da suspensão de CT aumentou o trânsito intestinal em 68,7 \% e os demais tratamentos apresentaram as seguintes percentagens: atropina 20,2 \%, acetilcolina 78,7 \% e controle 42,9 \% ( $<<0,05$, ANOVA seguido de teste de Tukey-Kramer). Esses resultados mostraram que a suspensão de CT estimulou o peristaltismo nos animais, o que sugere um efeito positivo na digestão e absorção alimentar para o consórcio microbiano.
\end{abstract}

Unitermos: Cogumelo tibetano, trânsito intestinal, probiótico.

\begin{abstract}
Effect of the administration of Tibetan mushroom, a microbial consortium, on the intestinal peristalsis in rats". The Tibetan mushroom (CT) is a probiotic beverage fermented by a big group of bacteria and yeasts, some of which of well-known anti-bacterial activity, immunomodulatory, pro-digestive and to aid of the intestinal peristalsis. In this sense, this work had the aim of evaluating the possible action of the suspension produced by CT on the peristalsis intestinal of rats. Animal groups weighing $200 \pm 20 \mathrm{~g}$ were used (Wistar rats (male, $\mathrm{n}=6 /$ group)). The different groups were treated v.o. for 15 days $(1,5 \mathrm{~mL} / \mathrm{animal}$ of $24 \mathrm{~h}$ fermented of CT in continuously cultured into molasses solutions $(50 \mathrm{~g} / \mathrm{l})$ ), and the other groups treated with distilled water (1,5 mL/animal). After 15 days the animals were maintained in fast for $24 \mathrm{~h}$, and treated with suspension CT (1,5 mL/animal/v.o), distilled water (control, 1,5mL/animal/v.o), acetylcholine (1mg/ $\mathrm{kg} / \mathrm{s} . \mathrm{c})$ and atropine (1mg/kg/i.m). After $30 \mathrm{~min}$, the animals received a suspension of active coal $10 \%(0,1 \mathrm{~mL} / 10 \mathrm{~g}, \mathrm{v} . \mathrm{o})$, after the euthanasia, excision of the portion of the pylorus to the beginning of the cecum, and determination of the distance traveled by the coal. The administration of the CT suspension increased the intestinal peristalsis in $68,7 \%$ and the other treatments presented the following percentages: atropine 20,2\%, acetylcholine 78,7\% and control 42,9\% ( $<<0,05$, ANOVA followed by Tukey-Kramer test). Those results showed that the CT suspension stimulated the peristalsis in the animals, what suggests a positive effect in the digestion and alimentary absorption for the microbial consortium.
\end{abstract}

Keywords: Tibetan mushroom, intestinal peristalsis, probiotic.

\section{INTRODUÇ̃̃̃O}

Os probióticos são suplementos microbianos vivos do intestino, que ingeridos, são capazes de se estabelecer no trato gastrintestinal e manter ou aumentar a microbiota natural, prevenindo a colonização por microrganismos patogênicos, e assegurando melhor utilização de nutrientes (Alves et al, 2000). Probióticos são comercializados como bactérias ou leveduras in natura, sob a forma de leites fermentados, iogurtes, ou de preparações contendo um ou vários microrganismos vivos (Nicoli; Vieira, 2000).

As leveduras têm ação diferenciada nos probióticos, podendo estimular processos microbianos de degradação e fermentação no ceco e cólon ou rúmen de animais adultos, enquanto em animais jovens têm ação 
complementar às bactérias probióticas [kmet et al., 1993]. Vários são os mecanismos reportados para explicar a ação dos probióticos no trato gastrointestinal: 1) exclusão competitiva (Ozawa e Yabu-Uchi, 1978), 2) competição por locais ou sítios de adesão na parede do aparelho digestório (Alves et al, 2000; Watkins; Miller, 1983), 3) produção de substâncias inibidoras (ácido acético, lático e bacteriocininas), 4) redução de pH (Fuller, 1989a ;Nicoli; Vieira, 2001), 5) inibição da produção ou ação de aminas tóxicas, 6) aumento da disponibilidade de aminoácidos nos locais de absorção (Kozasa, 1989), 7) aumento da síntese de enzimas digestivas e vitaminas do complexo $\mathrm{B}$, e 8) estimulo da imunidade inata e celular (Inooka et al, 1986).

O consórcio microbiano que se pretendeu avaliar possíveis efeitos pró-digestivos neste trabalho foi o cogumelo tibetano (CT). O CT é constituído por grãos gelatinosos e irregulares formados por uma associação simbiotica de leveduras e bactérias lácticas que causam uma fermentação ácido-alcoólica em açúcar e preparações de leite (Diniz et al., 2003). Essa associação às vezes é confundida com outras associações simbióticas da mesma natureza, como kumish e cogumelo kombucha (Pauline et al, 2001), presentes na medicina popular de países asiáticos. O CT pode ser distinguido daqueles pelo seu conteúdo microbiológico e estrutura morfológica (Diniz et al., 2003). O teor biótico do CT compreende bactérias de ácido lático, tais como lactobacilos (Lactobacillus casei, L. acidophilus), lactococos (Lactococcus lactis), leuconostocos (Leuconostoc citrovorum, L. mesenteroides), acetobactérias (Acetobacter aceti, A. rasens), e estreptococos (Streptococcus thermophilus, $S$. lactis), algumas também encontradas em iogurtes e leites fermentados, além de alguns fungos (Kluyveromuces sp, Sacharomyces sp).

Este trabalho teve como objetivo avaliar a existência de propriedades modulatórias do trato intestinal da suspensão fermentada de cogumelo tibetano.

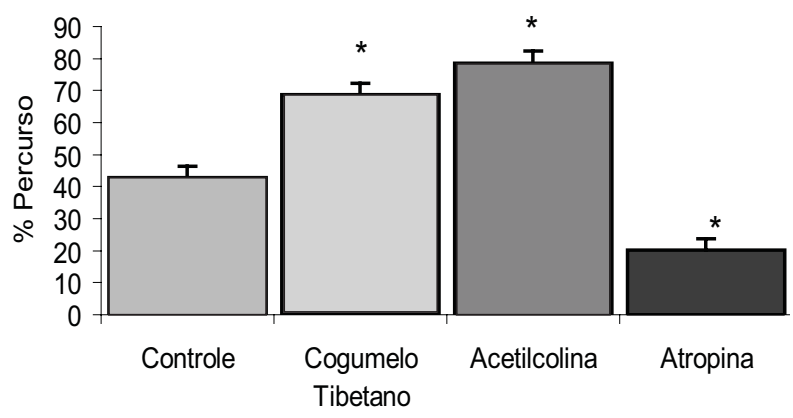

Figura 1. Efeito da suspensão de cogumelo tibetano $(1,5 \mathrm{~mL} /$ v.o./animal), atropina ( $1 \mathrm{mg} / \mathrm{kg} / \mathrm{i} . \mathrm{m}$.), acetilcolina ( $1 \mathrm{mg} / \mathrm{kg} / \mathrm{s.c}$.) e água destilada por via oral, sobre o peristaltismo intestinal de ratos Wistar albinos. $\mathrm{N}=6$ /grupo, $* \mathrm{p}<0,05$ (ANOVA seguido de teste de Tukey-Kramer).

\section{MATERIAL E MÉTODOS}

\section{Animais}

Foram utilizados grupos de animais (ratos Wistar albinos machos, $n=6$ /grupo) pesando $200 \pm 20$ g, que receberam ração comercial e água ad libtum. Os animais foram provenientes do Biotério Central da Universidade de Alfenas - UNIFENAS, Alfenas -MG, mantidos em caixas de polietileno em ambiente com temperatura controlada de $25 \pm 2{ }^{\circ} \mathrm{C}$ e ciclo claro-escuro de $12 \mathrm{~h}$. O protocolo experimental foi aprovado pelo Comitê de Ética da Universidade José do Rosário Vellano, sob Protocolo No 19A/2003.

\section{Cultivo e administração da suspensão de CT}

A suspensão simbiótica de CT foi cultivada continuamente em solução de açúcar mascavo dissolvido em água destilada (50 g/l), com troca contínua do material nutriente a cada 24 horas da cultura, até o desenvolvimento de pH para o fermentado de 4,6 (Diniz et al., 2003). A administração da suspensão simbiótica foi realizada diariamente durante 15 dias, na dose de $1,5 \mathrm{~mL} /$ animal/v.o, correspondente à dose utilizada popularmente no consumo humano de fermentados probióticos (200 a 400 mL para indivíduo adulto de 70 kg; Sallof-Coaste, 1996).

\section{Determinação da atividade da suspensão de Cogumelo tibetano sobre o trânsito intestinal}

Os diferentes grupos de animais foram tratados v.o. durante 15 dias com a suspensão de CT e os demais grupos tratados com água destilada. Após estes 15 dias, os animais foram mantidos em jejum por $24 \mathrm{~h}$ para esvaziamento gastrointestinal, e tratados com a suspensão de CT e com as substâncias padrões: acetilcolina (controle positivo, $1 \mathrm{mg} / \mathrm{kg} / \mathrm{s} . c$. , Sigma-Aldrich, St. Louis, MO, EUA), água destilada (controle negativo, $1,5 \mathrm{~mL} / \mathrm{animal} /$ v.o.), atropina (controle positivo, $1 \mathrm{mg} / \mathrm{kg}$, i.m., SigmaAldrich). Após 30 minutos, os animais receberam v.o. a suspensão de carvão ativo a $10 \%(0,1 \mathrm{~mL} / 10 \mathrm{~g}$, Lafan Quimica Fina Ltda, SP, Brasil). Decorridos 45 minutos, os animais foram submetidos a eutanásia e retirou-se a porção do piloro até o início do ceco segundo Ruwart (1980). A distância percorrida pelo carvão ativo foi medida do piloro à ultima porção do intestino, que continha pelo menos $1 \mathrm{~cm}$ contínuo de carvão. A distância percorrida foi expressa em porcentagem do comprimento total do intestino delgado. Os resultados foram expressos como médias \pm EPM e, para a comparação entre os grupos, foi utilizado ANOVA seguido de teste de Tukey-Kramer, com valores de $\mathrm{p}<0,05$ considerados estatisticamente significativos. 


\section{RESULTADOS E DISCUSSÃO}

A administração da suspensão de CT aumentou significativamente a peristalse intestinal (Figura 1, $\mathrm{p}<0,05$ ), o que pode ser constatado pela maior distância percorrida pelo carvão ativo no lúmem dos animais, em relação ao grupo controle tratado com água destilada. Esse efeito foi similar ao do grupo que recebeu acetilcolina, de conhecida influencia direta no esvaziamento e trânsito intestinal (Harvey; Champe, 1998), conforme avaliado pelo percurso estabelecido pelo carvão ativo no TGI dos animais. Como um antiespasmódico, a atropina promoveu uma redução significativa no trânsito intestinal dos animais em relação aos demais grupos $(\mathrm{p}<0,05)$, conforme esperado (Figura 1). Os resultados apresentaram ainda uma diminuição no odor das fezes do grupo tratado com CT, em relação aos demais grupos, o que segundo Hidaka \& Eida (1988) sugere uma alteração no metabolismo das proteínas, evitando a formação de substâncias putrefeitas e amoniacais, responsáveis por odores fetidos.

É conhecido que os mecanismos de ação propostos para explicar os efeitos benéficos dos probióticos são basicamente os mesmos utilizados pela microbiota normal no exercício de suas funções (Nicoli; Vieira, 2000). Assim, os microrganismos vivos quando utilizados como suplementos na dieta, favorecem o desenvolvimento da microbiota intestinal (Cagigas; Anesto, 2002). Esse favorecimento pode estar relacionado com a fermentação de resíduos dietéticos, como as fibras contidas na ração comercial empregada (máximo de 5\%), as quais podem estar relacionadas diretamente com o aumento da massa fecal e peristaltismo intestinal, paralelamente à produção de alguns metabólitos importantes para o organismo, como ácidos graxos de cadeia curta (Schneedorf, 2005).

Outros mecanismos podem ser propostos para elucidar os possíveis efeitos da suspensão de CT no TGI dos animais tratados, cuja ação foi similar a da acetilcolina. Esse mediador é conhecido atuar nos movimentos musculares segmentares ou propulsivos (peristaltismo e segmentação) do intestino, por inibição competitiva de enzimas, estimulação da adenilato-ciclase, ou aumento da permeabilidade da membrana celular, por ruptura da continuidade celular (Carvalho, 2005).

\section{CONCLUSÃO}

Estes resultados sugerem que a suspensão de cogumelo tibetano possui compostos que estimularam a atividade peristáltica nos animais. Este efeito probiótico poderia ser avaliado na redução da freqüência de episódios de diarréia, atraso na evacuação intestinal e irritação de sua mucosa, bem como em outros distúrbios do trato digestório.

\section{AGRADECIMENTO}

A Rede Mineira de Ensaios Farmacológicos e
Toxicológicos de Produtos Terapêuticos (FAPEMIG EDT 1879/02).

\section{REFERÊNCIAS}

Alves PAPM, Almeida MIV, Lizieire RS, Mosdesta RCD, Almeida FQ, Nascimento CGH 2000. Uso de probiótico composto por Lactobacillus acidophilus, Estreptococcus faecium e Sacharomyces cerevisae na dieta de vitelos bovinos. Braz J Vet Res Anim Sci 37: 1-15.

Cagigas ALR, Anesto JB 2002. Prebióticos y probióticos, una relacion beneficiosa. Rev Cuba Aliment Nutr 16: 6368.

Carvalho JCT 2005. Formulário médico-farmacêutico de fitoterapia. Alfenas, MG: Editora Ciência Brasilis, 343p.

Diniz R, Garla LK, Schneedorf JM, Carvalho JCT 2003. Study of antiinflammatory activity of Tibetan mushroom a symbiotic culture of bacteria and fungi encapsulated into a polysaccharide matrix. Pharm Res 47: 49-52.

Fuller R 1989. Probiotics in man and animals. A review. J Appl Bacteriol 66: 365-378.

Harvey RA, Champe PC 1998. Farmacologia ilustrada. Porto Alegre: Artmed, 478p.

Hidaka H, Eida T 1988. Role of fructooligosacharides in the imporvement of bacterial flora and in the control of decomposition product formation. Shokuhin Kogyo (Food Industry) 31: 52-58.

Inooka S, Uehara S, Kimura M 1986. The effect of Bacillus natto on the $\mathrm{T}$ and $\mathrm{B}$ lymphocytes from spleens of feeding chickens. Poultry Sci 65: 1217-1219.

Kmet V, Flint J, Wallace RJ 1993. Probiotics and manipulation of rumen development and function. Arch Anim Nutr 44: $1-10$.

Kozasa M 1989. Probiotics for animal use in Japan. Vet Sci Tech Off Int Epiz 8: 517-531.

Nicoli JR, Vieira LQ 2000. Probiótico, prebiótico e simbiótico: Moduladores do sistema digestivo. Ciência Hoje. 28: 35-38.

Ozawa K, Yabu-Uchi K 1978. Antagonistic effects of Bacillus natto and Streptococcus faecalis on growth of Candida albicans. Microbiol Immunol 23: 1147-1156.

Pauline T, Dipti P, Anju B, Kawimani S, Sharma SK, Kain AK, Sarada SK, Sairam M, Ilawazhagan G, Devendra K, Selvamurthy W 2001. Studies in toxicity, antihypertension and hepatoprotective properties of kombucha tea. Biomed Environ Sci 14: 207-213.

Ruwart MJ 1980. Clonidine delays smail intestinal transit in the rat. J Pharm Exp Ther 212: 487-490.

Schneedorf JM 2005. Bioquímica em agropecuária. Alfenas: Ciência Brasilis, 225p.

Watkins BA, Miller BF 1983. Competitive gut exclusion of avian pathogens by Lactobacillus acidophilus in gnotobiotic chicks. Poultry Sci 61: 1772-1779. 